\title{
Study of Debris Flow Mechanism in Tunnel Faults in Aqueous Environment
}

\author{
Suchao $\mathrm{Xu}^{1,2, \mathrm{a}}$ Shenshen $\mathrm{Yu}^{3, \mathrm{~b}}$
}

${ }^{1}$ School of architecture and Civil Engineering, Shenyang University, Shenyang, Liaoning 110044 , ChinaKey Laboratory of Liaoning Province for environmental geotechnical engineering, Shenyang, Liaoning 110044, China

${ }^{2}$ State Key Laboratory of Geomechanics and Geotechnical Engineering, Institute of Rock and Soil Mechanics, Chinese Academy of Science, Wuhan, Hubei430071, China

${ }^{3}$ Liaoning Administration of Coal Mine Safety, Shenyang, Liaoning 110042, China

axusuchao@163.coml, byuss_007@163.com

Keywords: prediction method, rockburst, elastic energy Index.

Abstract: In this paper, according to the debris flow problem in the region of karst through fault fracture zone, a test concerning the evolution of permeability for mud rock were carried out. Such conclusions were gained: initial deposition deformation and micro crack closing play a greater influence on the evolution of permeability and the stress induced damage play an important role in micro cracks extension and propagation stage; loosen and broken geotechnical structure and poor surrounding rock properties play a main role in engineering geological characteristics; aqueous environment is a non-sufficient but necessary factor for debris flow.

\section{Introduction}

In recent years, the fast development of tunnel engineering, the debris flow often happen and is becoming a more common geological disaster especially in the region of karst through fault fracture zone. Such disasters will lead construction suspended, machine destroyed, great economic losses and even casualties. From past project cases, it can be seen that the debris flow often occurred in aqueous environment. Due to the fault fracture zone of rock mass is loose, a great amount of mud gush out under high water pressure and often cause tunnel collapse. So it is urgent to do some research work on the study of permeability of this kind of rock.

\section{Introduction of Test Method}

In order to investigate the problems introduce above, we designed a testing method which is depicted as figure 1 . The principle of this test could be explained as follows: firstly, keep a certain water pressure at the upstream of the permeability channel (at the buttom of rock specimen) and make the downstream connected to atmosphere. Thus a stable water pressure difference is formed between upstream and downstream in the sample $(\Delta p)$. After the internal flow getting stable, the pressure difference $(\Delta p)$ and injection rate $Q\left(\mathrm{~m}^{3} \cdot \mathrm{s}^{-1}\right)$ will go to stable subsequently. According to the Darcy's Law, the intrinsic permeability $k$ can be calculated by the following function :

$$
k\left(m^{2}\right)=\frac{Q \mu L}{\Delta p A}
$$

In this function, $\mu$ is the coefficient of dynamic viscosity which value is $\mu=1.005 \times 10^{-3} \mathrm{~Pa} \cdot \mathrm{s}$ under the testing temperature. $L$ is the length of specimen and A is the cross-section area. 


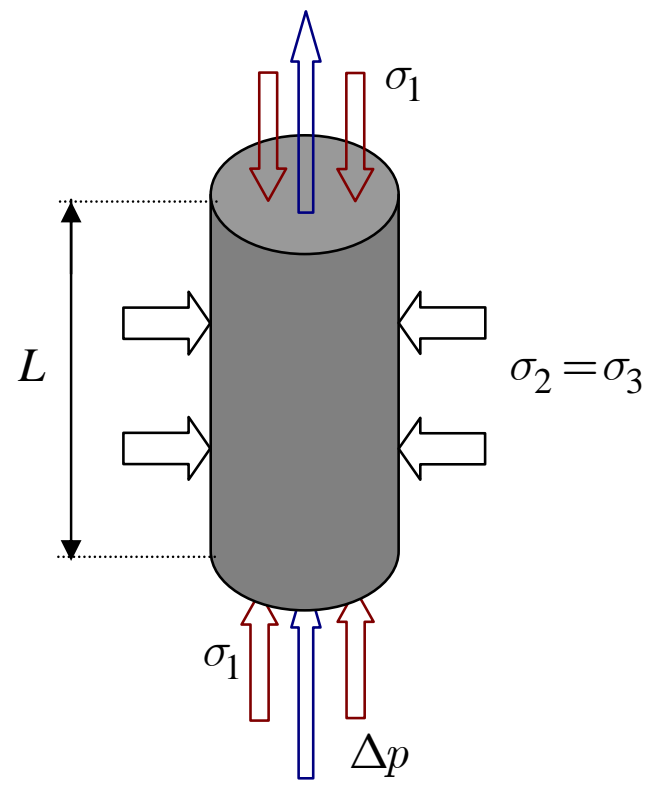

Fig 1. Permeability test skecth map

The purpose of this test is to obtain the variation characteristics of permeability under different biased pressure levels. Therefore, we conducted a series of tri-axial compression tests under different confining pressure, and carried out cyclic loading and unloading tests at different biased pressure levels, measuring the permeability at the beginning of each loading and unloading stage. Average value of upstream of injected fluid flow is $0.07 \mathrm{ml} / \mathrm{min}$.

\section{Results and Analysis}

According the above statement, we gained the results of stress-strain curves under permeability test and evolution rules of premeability-relative axial strain of 4 groups under different confining pressure (5,10,20 and 30Mpa).

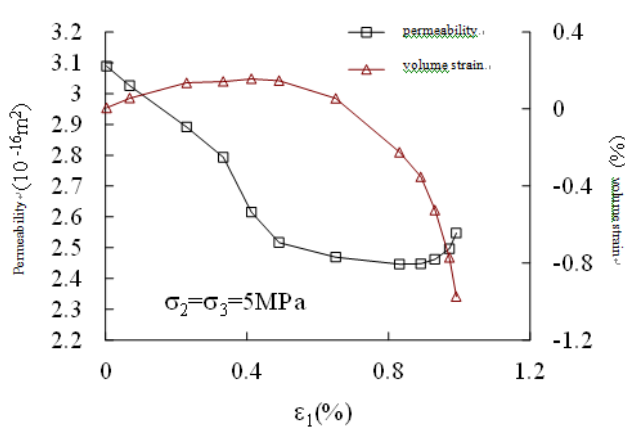

(a) confining pressure $5 \mathrm{MPa}$

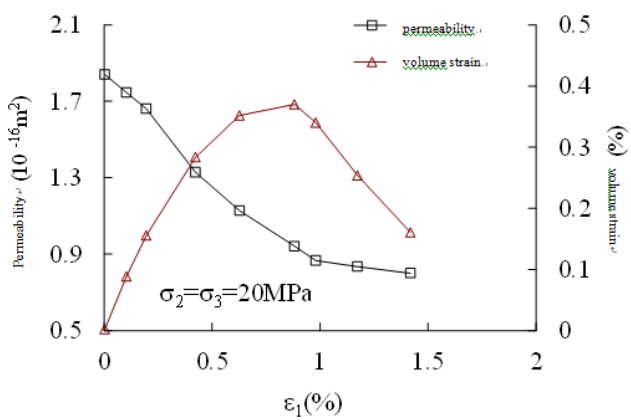

(c) confining pressure $20 \mathrm{MPa}$

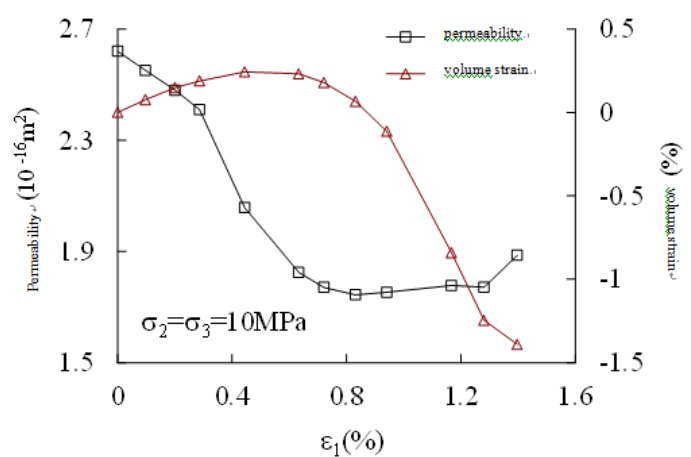

(b) confining pressure $10 \mathrm{MPa}$

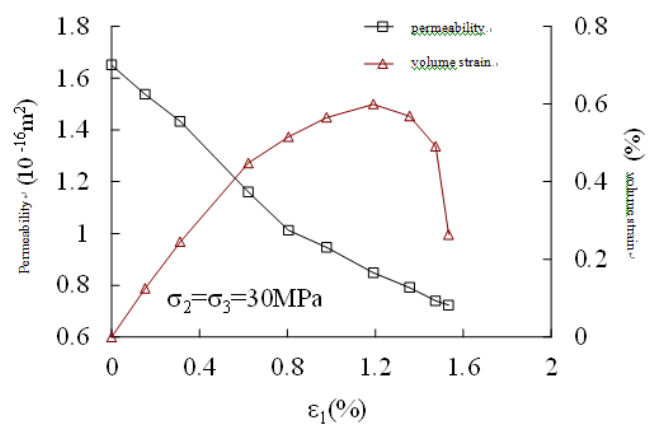

(d) confining pressure $30 \mathrm{MPa}$

Figure 2. Stress-Strain curves and permeability evolution curves under under different confining pressure 
From the observation under the condition of different confining pressure axial permeability evolution curve, we can find that there are two stages in rock deformation process which are initial deposition deforming stage and micro crack closing stage (linear elastic phase). In these two stages, its axial permeability decrease rapidly. After that, the stress induced micro crack began to conceive and axial permeability decreasing rate started to slow down, under the condition of low confining pressure, axial permeability even began to increase.

\section{Conclusions and Acknowlegement}

By the analysis above, we can come to the conclusions as follows:

1. In a relatively high initial permeability mud rock, compared with the stress induced damage, initial deposition deformation and micro crack closing play a greater influence on the evolution of permeability. In micro cracks extension and propagation stage, the stress induced damage effect on the evolution of permeability gradually become obvious.

2. Loosen and broken geotechnical structure and poor surrounding rock properties play a main role in engineering geological characteristics when debris flow occurs. When debris flow occurs, the main composition material is broken rock mass in fault fracture zone;

3. Aqueous environment is a non-sufficient but necessary factor for debris flow. The characteristics of debris flow process are obvious nonlinear behavior, such as nonlinear high speed seepage and nonlinear rock mass deforming, etc. So, it is necessary to carry out a series of research work about the problem of high water pressure and high velocity of debris flow.

This paper get financial support from the national natural science foundation of China (51304138) and fund of Liaoning province department of education(L2013451).

\section{Reference:}

[1]. Murdoch L C. Hydraulic fracturing of soil during laboratory experiments. Part 1. Methods and observations[J]. Geotechnique, 1993, 43(2): 255-265.

[2]. Xu-Suchao, FENG-Xiating, CHEN-Bingrui.Experimental study of skarn under uniaxial cyclic loading and unloading tests and acoustic emission characteristics [J]. Rock and Soil Mechanics, 2009, 30(10): 2929-2934.

[3]. Xu-Suchao, FENG-Xiating, CHEN-Bingrui. Acoustic emission characteristics and strength variation of skarn under true triaxial test.[J]. Rock Mechanics: Achievements and Ambitions. 2011, 215-218.

[4]. Xu-Suchao, CHEN-Bingrui, Jin-Changyu. Study on the Prediction Method for Brittle Failure of Hard Rock Based on Acoustic Emission Test [J]. Advanced Materials Research. Volumes 594 597.

[5]. Weijers L, Wright C A, Sugiyama H, et al. Simultaneous propagation of multiple hydraulic fractures-evidence, impact and modeling implications[C]//International Oil and Gas Conference and Exhibition in China. Society of Petroleum Engineers, 2000.

[6]. WILSON C. R., WITHERSPOON P. A. An investigation of laminar flow in fractured porous rocks [R]. California: University of California, Berkeley, 1970.

[7]. LOUIS C. Rock hydraulics[M]. Rock mechanics, L Muller, New York:Springer Wien, 1974, 299-382.

[8].GALE J. E. The effects of fracture type (induced versus natural) on the stress-fracture closure-fracture permeability relationships[C].Issues in Rock Mechanics: Proceedings of the 23rd US Symposium on Rock Mechanics. Rotterdam: Balkema. 1982. 